\title{
High-throughput gas phase transient reactor for catalytic material characterization and kinetic studies
}

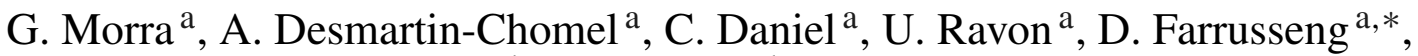 \\ R. Cowan ${ }^{\mathrm{b}}$, M. Krusche ${ }^{\mathrm{b}}$, C. Mirodatos ${ }^{\mathrm{a}}$ \\ a IRCELYON, Institut de recherches sur la catalyse et l'environnement de Lyon, Unité Mixte de Recherche \\ 5256 CNRS-Université de Lyon 1, 2 avenue Albert Einstein, F-69626 Villeurbanne Cedex, France \\ ${ }^{\mathrm{b}}$ AMTEC GmbH, Annaberger Strasse 240, 09125 Chemnitz, Germany
}

\begin{abstract}
This work presents an alternative approach for material screening, aiming at investigating under high throughput (HT) conditions key features like kinetic and thermodynamic parameters in catalysis and gas adsorption. A 16-parallel reactor was specifically designed for HT transient screening and kinetics. The fluidic system which enables parallel transient experimentation is detailed. Among its capabilities, this HT equipment allows one to evaluate (i) reaction kinetics under the same ageing conditions for a library of catalysts, and (ii) simplified aging kinetics as well for accessing proper conversion and selectivity data to be modelled. In the domain of adsorption, isotherms of pure component and gas mixtures can be measured by means of parallel breakthrough curve experimentation. The capability, versatility and limits of this equipment are demonstrated through the following case studies: (1) deactivation and kinetic study of $o$-xylene hydrogenation, (2) characterization of oxygen storage capacity (OSC) of metal/ceria-doped catalysts and (3) HT gas adsorption on microporous materials.
\end{abstract}

Keywords: High throughput catalysis; Combinatorial catalysis; Parallel reactor; Transient experimentation; Xylene hydrogenation; Oxygen storage; Gas adsorption; Pressure swing adsorption

\section{Introduction}

High-throughput (HT) screening relies on a fast testing of large libraries of compounds by using parallel reactors. This research methodology, massively applied for drug development, was extended to Material and Catalysis science in the late 1990s. Commonly, a HT research project can be carried out in two stages. The primary stage consists at screening large and as diverse as possible libraries to identify promising candidates called "hits." The latter are then optimized in a secondary screening stage with targeted libraries. The primary screening is usually characterized by a high degree of parallelization and a very fast or parallel analysis while the secondary screening is driven by higher quality data which are obtained under more realistic operating conditions and shall consider scale-up issues, fluid dynamic and process control.

\footnotetext{
* Corresponding author.

E-mail address: david.farrusseng @ircelyon.univ-lyon1.fr (D. Farrusseng).
}

Numbers of parallel experimental set-ups were developed for gas-phase reaction. An overview of current developments can be found in $[1,2]$. HT testing equipments for primary screening can be divided into two categories. The first ones are monolith or micro-channel type reactors in which each channel is coated with a catalyst layer having a specific composition [3-7]. The second ones are addressable arrays of thin films on wafers [8-11] or single beads [12]. In most cases, the gas phase is analysed by mass spectrometry using a sampling capillary mounted on a XY robotic actuator to test all the catalysts individually and sequentially. In contrast, HT testing equipments for secondary screening are usually fixed bed reactors with catalyst loading in the range of $20-200 \mathrm{mg}$. They consist in multi-tubular reactor modules made of steel, quartz or ceramics [13-24].

Although the secondary screening provides a quantitative evaluation of catalytic performances under operating conditions close to the real applications, much more detailed investigations on catalytic performances must be carried out before scaling up the best selected systems towards mini-pilot scale reactors. This stage, also called tertiary screening, comprises catalysts 
activation/deactivation studies, kinetic studies, mass and heat transfer analysis, poisoning under real inlet gases and catalyst characterization, in and/or ex situ $[25,26]$. Secondary and tertiary screenings are operated on a reduced number of materials. A few numbers of parallel equipments were developed for these purposes. Perez-Ramirez et al have designed a six flow reactor setup was for HT kinetic studies [27]. The key feature of the catalytic bench relies on the fluid feeding system which enables to feed each of the six reactors at a different flow rate or pressure while the proportion of reactant remains the same. This design is very well appropriate when one looks at adjusting the contact time to obtain many conversion data points in appropriate ranges for kinetic modelling. The "Spider"TM" reactor, developed by Serra et al, consists of 16 parallel high-pressure reactors which can be fed independently for oil refining applications [18].

Whatever the degree of sophistication of these reactors, a key type of catalytic processes can hardly be caught correctly. They relate to catalytic instability phenomena like activation/deactivation processes occurring during steady-state operations, or catalyst behaviour under transient operating conditions which may correspond to permanently unsteady processes employing moving or fluidized bed, post-combustion, reverse flow reactors, domestic applications, etc.

If one considers for example deactivation processes, their rates depend usually on catalyst formulation and operating conditions. In a sequential testing process, the first and the last catalyst of a loaded series of six or more catalysts are evaluated at very different time on stream, depending on the time required for analysing each sample. This generally results in bias activity values [14].

A way to tackle that issue is to perform HT kinetic studies on a truly parallel system. A 16-channel reactor system equipped with a spatially resolved FTIR was developed at the University of Delaware to perform kinetic measurements under truly parallel conditions [28]. The system was successfully applied for CO oxidation and NOx storages. In contrast to sequential analysis by gas chromatography and/or mass spectrometry, this system offers the opportunity to record catalytic measurements every 4-12 s for all catalysts which then enable to have access to kinetic data under controlled and similar time-on-stream conditions.

In this paper, a 16-parallel reactor designed for HT transient screening and HT kinetics is presented. The fluidic supply that enables parallel transient experimentation and the reactor modules are described. The capability, versatility and limits of the testing units are illustrated through a series of examples: (1) deactivation under steady-state conditions and kinetic study of $o$-xylene hydrogenation, (2) characterization of oxygen storage capacity (OSC) of ceria-doped catalysts by transient redox operations, and (3) HT gas adsorption isotherms on microporous materials by transient adsorption/desorption cycles. Another successful application dealing with transient temperature runaway during temperature programmed catalytic soot combustion will be reported in a forthcoming paper.

\section{Experimental}

\subsection{Reactor system for fast material screening}

A proprietary 16 channel-multitubular reactor (Fig. 1) which has now been commercialised as the SWITCH 16 reactor system by AMTEC GmbH [29] - was jointly developed within the frame of a joint EU program [30] by IRC-CNRS and AMTEC.

The fluidic supply consists of a combination of two separate feed delivery modules and two 16-port valves that are placed before and after the multi-channel reactor array. The reactors are made from Inconel 600 and are connected to the inlet and outlet lines using VCR fittings, and have internal diameters of $7 \mathrm{~mm}$. They can be operated at up to $600^{\circ} \mathrm{C}$ and 13 bars. Each feed delivery module is equipped with five mass flow
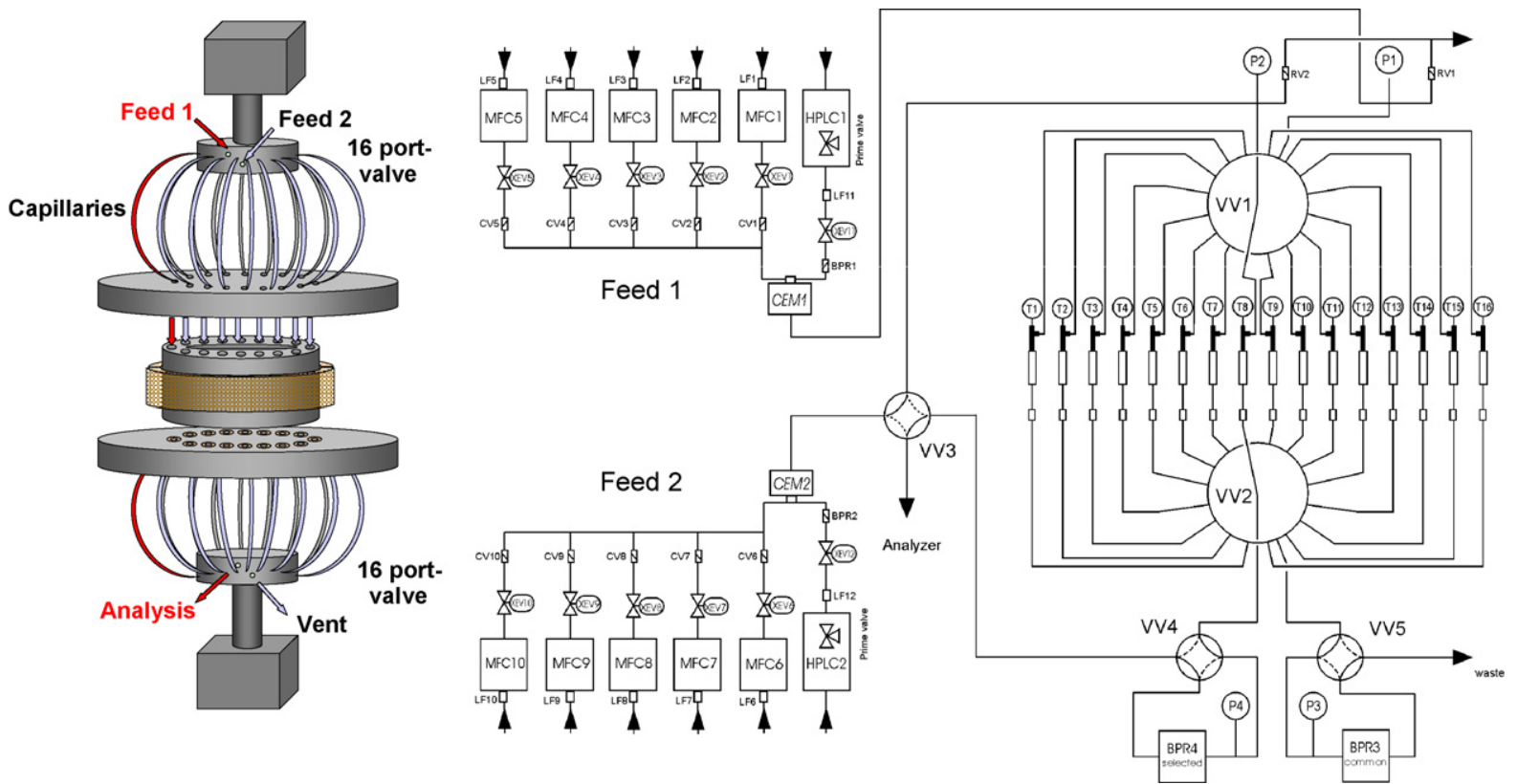

Fig. 1. Operating principle of the multi-channel reactor (left), and flow scheme (right). 


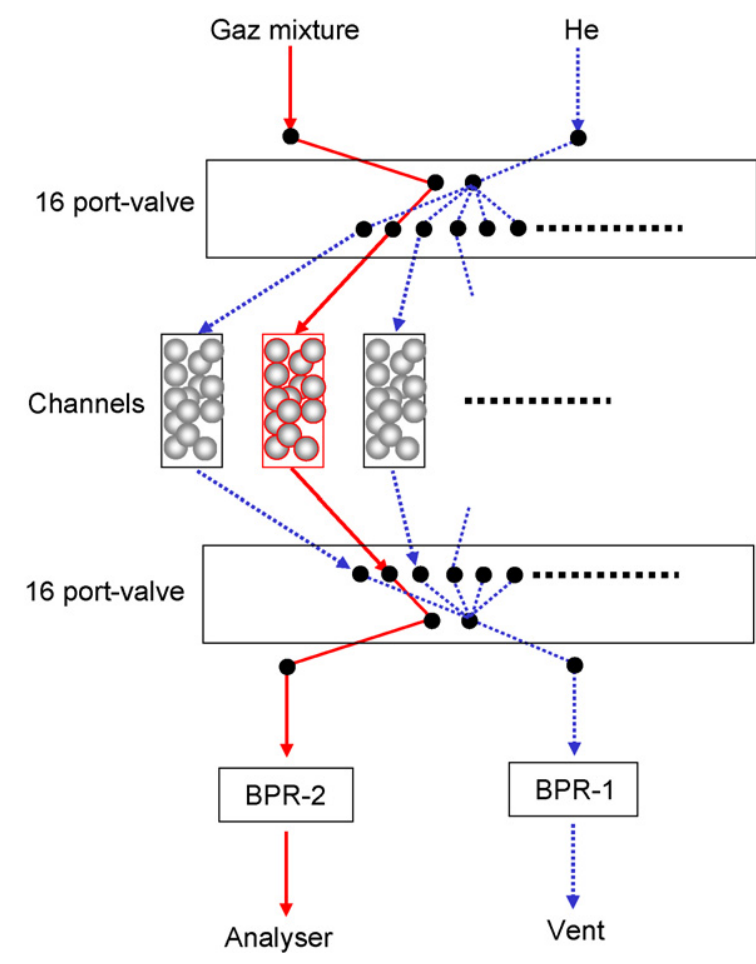

Fig. 2. Feed system scheme showing the two 16-port valve positions and flow through the selected reactor.

controllers (MFC) and a controlled evaporator mixer (CEMBronkorst). All the tubing and valves can be heated in order to prevent vapour condensation. The upper 16-port valve enables transient experimentation to be carried out in all 16 channels. The two 16-port valves can be synchronized so that when the upper valve switches to a given channel the lower valve selects the corresponding outlet channel which is connected to analytical systems. This system thus offers the opportunity to feed one selected reactor with a selected feed composition (Feed 2) while the 15 others are fed with a second composition (Feed 1), which can be identical to or different from Feed 1 (Fig. 2). This design has several advantages regarding testing capabilities and the type of experiments that can be carried out, that is, it is possible to evaluate catalysts under exactly the same ageing period and more specifically to measure the initial activity of each catalyst. Testing conditions can be varied in the selected channel while the other channels are maintained under standard or inert conditions, and in addition, catalyst deactivation can be studied in the selected channel while the 15 other channels are being regenerated. Finally, the design ensures that very accurate and reproducible flows are guaranteed in the selected channel by the 16-port valve. In the cases of permanent gas, the standard deviation is $0.4 \%$. It is usually higher in the case of vapours and it depends very much of pressure, flows and nature of vapours. In the case of xylene hydrogenation the partial pressure of xylene is measured with a standard deviation of $4 \%$. Conversion calculations are based on the partial pressure of $n$-heptane used as internal reference. There is therefore no need to use flow restrictors, which is an asset when acquiring suitable transient signals. However, in case of steady state experimentations (not reported here), flow constrictor systems can be used to guarantee equal flow distribution in the 15 other channels. Downstream, both lines are equipped with mechanical back pressure regulators (BPR) which control pressure in the common and selected lines. The back pressure regulators can be bypassed if required.

In the next presented case studies, the reaction products were monitored by gas chromatography and/or on-line mass spectrometry. GC analysis was performed by using an Agilent 3000 version QUAD instrument equipped with a four-channel module. Channel A was used for $\mathrm{H}_{2}, \mathrm{O}_{2}, \mathrm{~N}_{2}, \mathrm{CH}_{4}$ and $\mathrm{CO}$ measurements (MolSieve 5A, BF PPU Plot, with Ar as carrier gas), Channel B for $\mathrm{CO}_{2}$ and $\mathrm{H}_{2} \mathrm{O}$ (PPU, BF PPQ, with $\mathrm{He}$ as carrier gas). Channel C for cis- and trans-dimethyl-cyclohexane (OV1) and Channel D for $o$-xylene quantification (Stabilwax). Mass spectrometer (SM) analysis was performed using an Inficom $\mathrm{CPM}$ instrument.

\subsection{Case study 1: kinetic studies of o-xylene hydrogenation}

\subsubsection{Background and objective}

Toluene and xylenes are typical model molecules used for fundamental studies on the hydrogenation of aromatic hydrocarbons which takes place in petro-chemical refinery units. In contrast with most of combinatorial studies where the catalyst optimization for higher activity or selectivity is targeted, the search of relationships between the catalyst descriptors (metal nature, dispersion, support interaction, doping effects) and the catalytic performances is the main objective when investigating model reactions. Although the model reaction of $o$-xylene hydrogenation is investigated for several decades, its mechanism is still a matter of debate. A number of conceptual reaction pathways were introduced such as the stepwise [31], rollover [32] and interfacial [33] mechanisms. Usually a kinetic model is supported by experimental data on a specific class of catalysts and the extrapolation of the derived model to other systems is always questionable. The investigation of a kinetic model which holds for diverse catalysts whatever be the active metallic sites, dopants and supports meets this above mentioned objective for searching quantitative relationships between catalyst description and catalytic performance.

Another major issue to be tackled for any kinetic study is deactivation phenomena (carbon deposits, particle growth, metal/support interaction, alloy formation or demixing) which may be specific for each tested catalyst and which cannot a priori be predicted. This issue may be even more critical during HT parallel investigation. When a catalyst is under testing, the deactivation of other catalysts is not monitored. Indeed, the choice of catalytic systems that do not deactivate with time on stream will overcome any aging issues during parallel screening [14]. However, this extremely restrictive solution cannot be envisaged in any industrial oriented project. The investigation of aging kinetics is therefore a prerequisite for handling properly reaction kinetics.

This first case study aims at acquiring a pool of kinetic data in view to further discriminate various kinetic models, while monitoring correctly the catalyst ageing all along the kinetic 
Table 1

Selected catalysts which display diverse formulation, initial activity and deactivation profile in $o$-xylene dehydrogenation

\begin{tabular}{lcll}
\hline Catalyst ID & $\begin{array}{l}\text { Metal } \\
\text { content (wt.\%) }\end{array}$ & Support & $\begin{array}{l}\text { Catalyst } \\
\text { weight (mg) }\end{array}$ \\
\hline 1 & $0.5 \mathrm{Rh}$ & Low surface $\mathrm{Al}_{2} \mathrm{O}_{3}$ & 30 \\
2 & $0.5 \mathrm{Ni}, 0.16 \mathrm{Mo}$ & Low surface $\mathrm{Al}_{2} \mathrm{O}_{3}$ & 50 \\
3 & $0.5 \mathrm{Pd}$ & Low surface $\mathrm{Al}_{2} \mathrm{O}_{3}$ & 50 \\
4 & $0.5 \mathrm{Rh}, 0.19 \mathrm{In}$ & High surface $\mathrm{Al}_{2} \mathrm{O}_{3}$ & 30 \\
5 & $0.5 \mathrm{Pt}$ & Low surface $\mathrm{Al}_{2} \mathrm{O}_{3}$ & 50 \\
6 & $4 \mathrm{Ni}, 0.77 \mathrm{In}$ & Low surface $\mathrm{Al}_{2} \mathrm{O}_{3}$ & 100 \\
7 (benchmark) & $0.3 \mathrm{Pd}$ & Low surface $\mathrm{Al}_{2} \mathrm{O}_{3}$ & 200 \\
\hline
\end{tabular}

Catalyst \#7 was characterized and tested in details and is used as a reference benchmark.

campaign. Only the initial part of this study will be presented here, to demonstrate the capability of the equipment.

A library of 100 bi-metallic catalysts supported on various supports was prepared and tested in the hydrogenation of $o$ xylene. For sake of clarity, only a selection of six representative catalysts is presented here (Table 1), characteristic of diverse catalytic properties (high/low activity and deactivation shapes) and catalyst formulation (metals and supports). Results on the whole library will be reported elsewhere.

\subsubsection{Methodology}

The deactivation study was first carried out by testing the catalysts one by one for about $1 \mathrm{~h}$, that is, contacting each one with the reacting mixture while the others are maintained under $\mathrm{H}_{2} / \mathrm{N}_{2}$ flow. The switching protocol described in the experimental section was used for this purpose. Several equations were investigated to model the observed deactivation profiles. Then, kinetic data were obtained by varying $\mathrm{H}_{2}$ partial pressure and contact time (total flow) for a given catalyst at a given temperature. When the whole set of experimental conditions is completed, the catalyst is placed in the initial conditions applied for deactivation studies and analyses are performed. Next, the selection valve switches to the next catalyst. At the end of the cycle (16 catalysts), the whole heating block is set to the next temperature dwell and the next cycle is started as soon as the temperature is stabilized.

\subsubsection{Testing conditions}

For the initial deactivation study, catalysts are tested with a stream of $0.5 \%(\mathrm{~mol}) o$-xylene, $5 \%(\mathrm{~mol})$ heptane, $25 \%(\mathrm{~mol})$ hydrogen and nitrogen as diluent (Feed 2). The other channels are maintained under $\mathrm{H}_{2} / \mathrm{N}_{2}$ flow (Feed 1). The catalysts are previously reduced under $\mathrm{H}_{2}$ at $400{ }^{\circ} \mathrm{C}$ for $2 \mathrm{~h}$.

For the kinetic study, reactors are loaded with 50, 100, 200 or $400 \mathrm{mg}$ of catalysts depending on their previously measured activity. The $\mathrm{H}_{2}$ partial pressure was varied from $0.5 \%(\mathrm{~mol})$ to $48 \%$ (mol), the temperature from 100 to $200^{\circ} \mathrm{C}$ and the total flow from $20 \mathrm{~mL} \mathrm{CNTP}_{\mathrm{C}} / \mathrm{min}$ to $50 \mathrm{~mL} \mathrm{CNTP}_{\mathrm{C}} / \mathrm{min}$. Each $\mathrm{GC}$ analysis was duplicated.

Generally speaking, it was observed that conversion can attain the thermodynamic equilibrium for one catalyst but is below detection limits for a second one although the two tested systems have "similar" compositions. As an example, the doping of $\mathrm{Pd} /$ alumina catalyst with Ge can multiply the activity by a factor 20 [34]. This parameter sensitivity causes experimental issues when one wants to investigate kinetics. As a consequence, the catalyst mass in the channel, that is, contact time, must be adjusted with respect to the initial activity in order to measure conversion and selectivity in appropriate ranges (outside diffusion regime but being large enough to be correctly measured) for further kinetic modelling.

\subsubsection{Kinetic modelling}

In order to test different kinetic models, a catalyst (catalyst \#7) which does not deactivate and shows low conversion in the experimental conditions was selected as reference catalysts. A large dataset of more than 200 data points was collected and used as benchmark for model discrimination study and to simulate the impact of deactivation rates on the kinetic parameters.

About 10 different existing models and derivatives were investigated, from simple power-law to more advanced models based on diverse mechanism steps. For the present study, the selected model (referred to as Cin1) assumes that the adsorption of reactants is competitive and $\mathrm{H}_{2}$ does not dissociate. It can be described by the following steps:

$$
\left.\begin{array}{c}
\mathrm{A}+* \stackrel{K_{\mathrm{A}}}{\longrightarrow} \mathrm{A} * \\
\mathrm{H}_{2}+* \stackrel{K_{\mathrm{H}}}{\longrightarrow} \mathrm{H}_{2}^{*} \\
\mathrm{~A}^{*}+2 \mathrm{H}_{2}^{*} \stackrel{K_{\mathrm{AH}_{4}}}{\longleftrightarrow} \mathrm{AH}_{4}^{*}
\end{array}\right\} \text { Equilibrated, }
$$

where A stands for the aromatic, $\mathrm{C}$ and $\mathrm{T}$ for cis-DMCH and trans-DMCH, respectively $[32,35,36]$.

A rate equation for $o$-xylene conversion was built accordingly and it was also checked that no diffusion limitations occurred under the testing conditions. For that, the criterion $\tau=-\ln (1-X) / k$, where $\tau$ is contact time; $X$, conversion; $k$, rate constant, was found to be fulfilled for all tested catalysts.

\subsection{Case study 2: oxygen storage capacity measurements on ceria-doped catalyts}

\subsubsection{Background and objective}

Ceria-based mixed oxides $\left(\mathrm{Ce}_{x} \mathrm{M}_{1-} \mathrm{O}_{y}\right)$ are versatile solid oxygen exchangers. At high temperatures $\left(400-800{ }^{\circ} \mathrm{C}\right)$ the redox cycle $\mathrm{Ce}^{3+} \Leftrightarrow \mathrm{Ce}^{4+}+\mathrm{e}^{-}$facilitates oxygen storage and release from the bulk fluorite structure. In addition, the surface redox chemistry of ceria is sensitive even at low temperatures to crystal structure defects [37] which can be tuned by substituting some of the Ce cations with ions of different size and/or charge [38,39]. This makes them ideal candidates for catalytic oxidation applications where their oxygen storage capacity (OSC) can be used in a dynamic way, such as the three-ways catalysis, and/or the hydrogen production under non-stationary conditions [40].

This second case study aims at showing how the effects of doping the ceria support of platinum based catalysts on OSC can 
be investigated using the parallel testing reactor set-up above presented, aiming at discovering new materials [41].

\subsubsection{Methodology}

A set of 12 catalysts containing $2 \mathrm{wt} \% \mathrm{Pt}$ on $\mathrm{Ce}_{0.9} \mathrm{M}_{0.1} \mathrm{O}_{x}$ was prepared (where $\mathrm{M}=\mathrm{Pb}, \mathrm{Bi}, \mathrm{Zr}, \mathrm{V}, \mathrm{W}, \mathrm{Mo}, \mathrm{Y}, \mathrm{La}, \mathrm{In}, \mathrm{Sn}$, and two combinations of $\mathrm{Zr} / \mathrm{Bi}$, respectively) by impregnating platinum on various doped ceria supports. In practice, one reactor channel was loaded with a dopant free high surface area $\mathrm{Pt} / \mathrm{CeO}_{2}$ catalyst for comparison. The temperature was varied stepwise from 100 to $200^{\circ} \mathrm{C}$ every $20^{\circ} \mathrm{C}$. OSC measurements were quantified by $\mathrm{H}_{2}$ consumption in transient mode using the parallel reactor under isothermal conditions: Catalyst samples were oxidised in air for $15 \mathrm{~min}$, then flushed with $\mathrm{N}_{2}$ and then reacted with a reducing mixture of $10 \% \mathrm{H}_{2}$ in $\mathrm{He}$ while measuring continuously the hydrogen consumption by the Mass spectrometer for 3 min. While one sample was analyzed under $10 \% \mathrm{H}_{2}$ flow, the other ones were maintained under $\mathrm{N}_{2}$ flow. After a cycle was completed, the temperature was increased by $20^{\circ} \mathrm{C}$ and a new cycle started following the previous experimental sequence.

\subsection{Case study 3: adsorption isotherms of microporous materials}

\subsubsection{Background and objective}

The selective capture of carbon dioxide is a major objective for any large-scale process, $\mathrm{CO}_{2}$ being one of the main greenhouse effect gases. For instance its separation from methane is required in the processing of natural gas. Generally, pipeline specifications for natural gas require a carbon dioxide concentration below $3 \%$. The technology most widely used for carbon dioxide removal is amine absorption, but amine plants are costly and subjected to strong environmental constraints. An alternative, which is more recently applied, is the removal of carbon dioxide by means of an adsorption process. Pressure swing adsorption (PSA) technology has gained interest due to low energy requirements and low capital investment costs. Its main issue is to find an appropriate adsorbent which shall adsorb selectively one component over a mixture while not being adsorbed too strongly, otherwise the regeneration step can negatively affect the economy of the process. Separation by PSA can be based either on the different adsorption affinity of the components (thermodynamic separation), or on the different diffusion rates in the adsorbent (kinetic separation) [42,43]. For thermodynamic separation, the two key criteria of adsorbent effectiveness are the working capacity (WC) and the working selectivity (WS). The definition of working capacity is given in Eq. (1):

$\mathrm{WC}_{\mathrm{A}}=Q_{\mathrm{A}}(x, P, T)_{\mathrm{ads}}-Q_{\mathrm{A}}(x, P, T)_{\mathrm{des}}$

where $Q_{\mathrm{A}},(x, P, T)_{\text {ads }}$ and $Q_{\mathrm{A}},(x, P, T)_{\mathrm{des}}$ are the equilibrium loadings of A (mol $/ \mathrm{g})$ corresponding to the gas phase mole fraction $(x)$, total pressure $(P)$ and temperature $(T)$ at adsorption and desorption steps, respectively. The working capacity physically represents the net amount of adsorbate transacted on and off of the adsorbent for each complete cycle, providing a good indication of the amount of adsorbent required for the separation.
The working selectivity of component A relative to component B (defined in Eq. (2)) is a key indicator since it represents the separation efficiency. The operating conditions will dictate the selectivity and hence the performances of the adsorbents.

$\alpha=\frac{\mathrm{WC}_{\mathrm{A}}}{\mathrm{WC}_{\mathrm{B}}}$

Here, the adsorption isotherms are assumed to follow Langmuir behaviour; that is, the sorbents exhibit monolayer coverage as the saturation pressure is approached and have an energetically homogeneous surface. However, this parameter can be easily extended to other adsorption models as well. Isotherms were modelled using the Langmuir equation for a single component which can be written in the following form:

$Q=\frac{Q_{\text {sat }} K p}{(1+K p)}$

where $K=k \exp (-\Delta H / R T)$ and $p$ is the partial pressure of the single component in the diluted feed.

This third case study aims at demonstrating the ability of the Switch 16 set-up for rapidly acquiring the above described key indicators for $\mathrm{CO}_{2}$ adsorbent screening.

\subsubsection{Methodology}

The adsorption isotherms are calculated from breakthrough curves measurements taken at different total pressure [44]. Breakthrough curves consist at quantifying gas uptakes of an adsorbent bed in a transient operating mode. A gas mixture is sent to a selected channel for which the pressure is fixed at a given value. Partial pressures are measured on line by MS for a few minutes till the adsorbents get saturated. While adsorption measurements take place at the selected channel, the other channels are flushed under He flow to allow gas desorption for next measurements under different conditions of temperature and/or pressure.

In the reported study, channels are loaded with $200 \mathrm{mg}$ of sieved adsorbents. The feed is a gas mixture of $12.5 \% \mathrm{CO}_{2}$, $12.5 \% \mathrm{~N}_{2}$ in $\mathrm{He}$ with a total flow rate of $40 \mathrm{ml} \mathrm{min}^{-1}$. The breakthrough curves were recorded at different total pressure from 1.4 to 6 bars. The adsorbents are zeolites supplied by ENI Technology (NaX, NaY, NaZSM5, KL, NaBeta) and purchased from Flucka for 13X or made at the laboratory (NaZSM5 with $\mathrm{Si} / \mathrm{Al}=27,240$ ). Microporous metal organic frameworks $\mathrm{Cu}_{2}\left(\mathrm{BTC}_{3}\right)$ and a second undisclosed compound were prepared by precipitation.

\section{Results and discussion}

\subsection{Kinetic studies of o-xylene hydrogenation}

\subsubsection{Deactivation processes}

The deactivation decay curves acquired for six representative catalysts over a period of several hours are reported in Fig. 3. As can be seen, the more active the systems, the more it is deactivating. Two general aging trends were observed: an initial exponential deactivation for all catalysts in the very first hours on stream, followed/or not by a linear deactivation. These two 

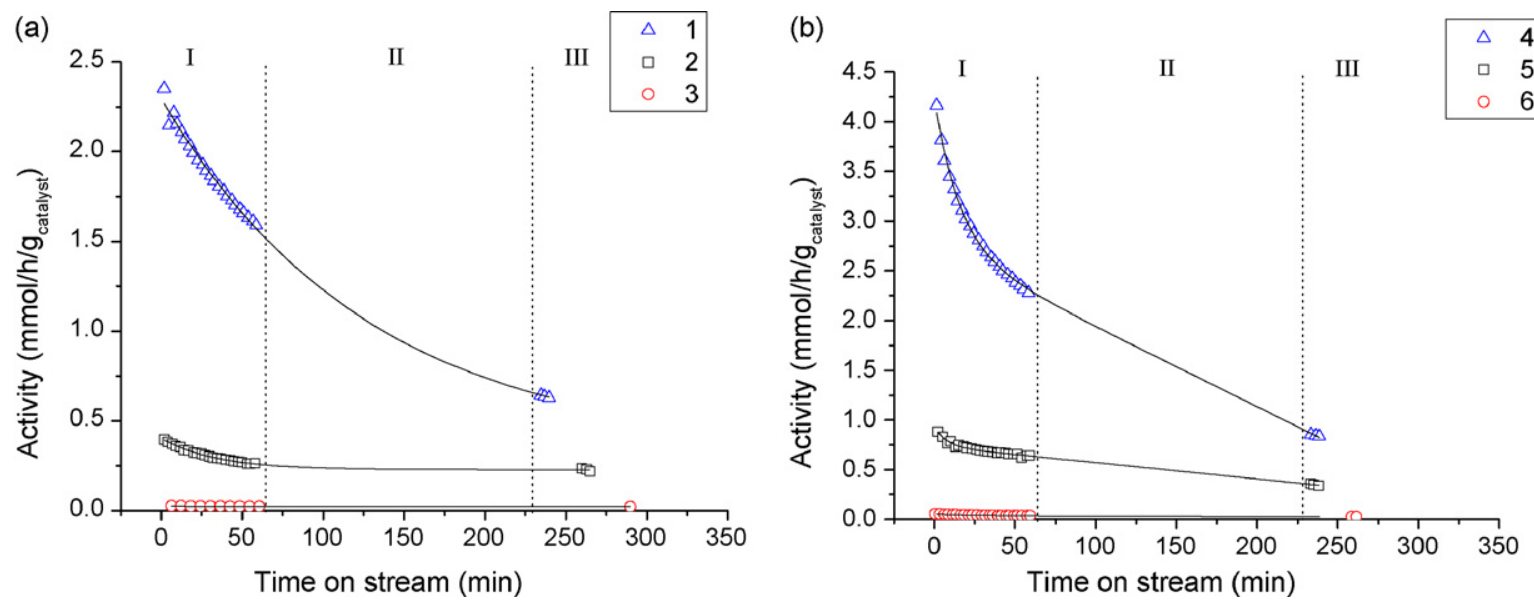

Fig. 3. Deactivation profiles during $o$-xylene hydrogenation for six selected catalysts. (a) Exponential (Deac1) and (b) exponential + linear (Deac2) decay models. Part I (from 0 to $60 \mathrm{~min}$ ) corresponds to the collection of deactivation data; Part II (from 60 to $250 \mathrm{~min}$ ), to the collection of kinetic data and Part III, to the acquisition of data in the initial deactivation conditions after $4 \mathrm{~h}$ on stream.

types of deactivation profiles were described by a simple exponential model (Deac1) or by a combination of an exponential and a linear model such as (Deac2)

$A=A_{\infty}+k \mathrm{e}^{-(t / \tau)}\left(\right.$ Deac1) $\quad A=A_{\infty}-v t+k \mathrm{e}^{-(t / \tau)}($ Deac2)

where $A$ is the activity; $A_{\infty}$ is the residual activity; $v$ is the rate of linear decrease; $k$ is the pre-exponential factor and $\tau$ the relaxation time.

For both deactivation types, three catalysts exhibiting high (catalysts \#1 and \#4), medium (catalysts \#2 and \#5) and low activities (catalysts \#3 and \#6) are presented. As such, the range of initial conversions spans from $20 \%$ for catalysts \#1 and \#4 to $1 \%$ for catalyst \#6.

Concerning the possible models for activity decay with time on stream, let us briefly recall that according to Levenspiel [45], the most general expressions are summarized in Table 2.

For the present case of $o$-xylene conversion, no concentration dependency was evidenced, (i.e., rate of decay was essentially independent of $o$-xylene, hydrogen or DMCH concentration). Additional TPO experiments performed on spent catalysts have shown that coke deposition occurred on deactivated samples. Therefore coking effects may be the cause of this activitydependant poisoning. A mechanism by coke deposition which encapsulate the metal particles and/or block the pores by deactivation progressively the catalyst bed from top to bottom of the reactor would qualitatively fit with the observed decay curves.

Table 2

Summary of deactivation models

\begin{tabular}{lll}
\hline Activity decay & Concentration-dependence & Aging rate equation \\
\hline Independent & None & $-\mathrm{d} a / \mathrm{d} t=k_{\mathrm{d}} a^{\mathrm{m}}$ \\
Parallel & Reactant A & $-\mathrm{d} a / \mathrm{d} t=k_{\mathrm{d}} C_{\mathrm{A}}^{\mathrm{n}} a^{\mathrm{m}}$ \\
Series & Product B & $-\mathrm{d} a / \mathrm{d} t=k_{\mathrm{d}} C_{\mathrm{B}}^{\mathrm{n}} a^{\mathrm{m}}$ \\
Side-by-side & Feedstock impurity P & $-\mathrm{d} a / \mathrm{d} t=k_{\mathrm{d}} C_{\mathrm{P}}^{\mathrm{n}} a^{\mathrm{m}}$ \\
\hline
\end{tabular}

a is the activity relative to fresh catalyst at a fixed point in a catalyst bed; $k_{\mathrm{d}}$ deactivation rate constant; $C$ is the concentration of reactant $\mathrm{A}$, product $\mathrm{B}$ or feedstock poison $\mathrm{P} ; \mathrm{n}$ and $\mathrm{m}$ are orders of decay on concentration and activity, respectively.
In addition, better fits were observed in most cases when an overlaying linear trend is added to the initial exponential model. This linear and constant deactivation, independent from activity, is assumed to be limited in time (for sake of model validity). This underlying mechanism could be a non-selective poisoning of the catalytic bed coming from a toxic component contained in the feedstock (e.g. traces of oxygen or of another pollutant). It would be classified as a side-by-side activity.

Indeed, these speculations require further analyses, such as establishing the decay rates as a function of coke contents (via advanced coke deposition kinetics acquired on an oscillating thermobalance TEOM, for instance) which might ascertain the decay origin. However, within the scope of the present study, this advanced knowledge of the aging process is not required for further discrimination of the reaction kinetics.

Table 3 presents the results of the aging modelling. As mentioned above, catalyst \#7 showed no deactivation and has been used as a benchmark to test kinetics models and to simulate the deactivation impact. As previously noted, the most active catalysts show the biggest global deactivation. Although catalysts \#3 and \#7 have similar compositions, they thus behave quite differently in terms of deactivation (catalyst \#3 activity dropped by near $20 \%$ within $5 \mathrm{~h}$ ). This may be due to the use of different precursors (palladium (II) acetate for catalyst \#3 and palladium (II) dichlorine for catalyst \#7) and of different synthesis protocols.

Depending on the model (Deac1 and 2), one or two times dependency parameters can be calculated. Since the exponential decay deactivation is activity dependant, the exponential relaxation time $\tau$ can be used as a catalyst deactivation descriptor. In contrast, the linear decreasing rate $v$ indicates a deactivation phenomenon which is independent of the activity. As a consequence, this parameter could be used to describe the interaction of a polluting environment on a specific catalyst.

\subsubsection{Deactivation and kinetic model integration}

The target to develop a methodology allowing a fast access to kinetic parameters for a large number of catalysts imposes that the number of experimental conditions tested shall be limited. 
Table 3

Results of deactivation kinetics

\begin{tabular}{|c|c|c|c|c|c|c|}
\hline Catalyst ID & $\begin{array}{l}\text { Deactivation } \\
\text { model }\end{array}$ & $\begin{array}{l}\text { Coefficient of } \\
\text { determination }\left(R^{2}\right)\end{array}$ & $\begin{array}{l}\text { Extrapolated activity } \\
\text { at } t_{0}\left(\mathrm{mmol} / \mathrm{h} / \mathrm{g}_{\text {cata }}\right)\end{array}$ & $\begin{array}{l}\text { Global deactivation } \\
{\left[\left(A\left(t_{0}\right)-A\left(t_{\text {end }}\right)\right) / A\left(t_{0}\right) ; \%\right]}\end{array}$ & $\begin{array}{l}\text { Decreasing rate } v \\
\left(\mathrm{~h}^{-1}\right)(\text { Deac } 2)\end{array}$ & $\begin{array}{l}\text { Relaxation time } \tau\left(\mathrm{h}^{-1}\right) \\
\text { (Deac1 and 2) }\end{array}$ \\
\hline \#1 & Deac1 & 0.99 & 2.29416 & 77 & - & 2.12 \\
\hline$\# 2$ & Deac1 & 0.99 & 0.40329 & 43 & - & 0.57 \\
\hline \#3 & Deac1 & 0.99 & 0.0269 & 18 & - & 0.86 \\
\hline \#4 & Deac2 & 0.99 & 4.22971 & 80 & 278 & 0.26 \\
\hline \#5 & Deac2 & 0.99 & 0.92671 & 67 & 57 & 0.13 \\
\hline \#6 & Deac2 & 0.99 & 0.05593 & 54 & 1.58 & 0.32 \\
\hline
\end{tabular}

In so far, kinetic parameters of the 100 catalysts were derived from 15 to 30 data points using the kinetic model presented in the section "Experimentals."

We first have investigated the ability of the model to describe catalyst performances while deactivating by using raw kinetic data, that is, not corrected from deactivation. Fig. 4 shows that the kinetic model Cin 1 is able to adequately describe both deactivating (catalyst \#3b) and non-deactivating (benchmark catalyst \#7) systems from type Deact1. Similarly, the model predicts as well the activity for a system of type Deact2 (catalyst \#6) despite a strong deactivation (about 50\%) in the period where kinetic data are collected.

This means that one cannot use the standard deviation between experimental and calculated data to discriminate experiments strongly influenced by the deactivation from experiments little or not affected by deactivation.

Quantification of the impact of deactivation on kinetic parameters was studied. Kinetic parameters were calculated by applying diverse rates of deactivation on the basis of the above-described aging models (see extrapolated activity at $t_{0}$ $\left(\mathrm{mmol} / \mathrm{h} / \mathrm{g}_{\text {cata }}\right)$ in Table 2$)$. Complete release of the methodologies and results will be published in a forthcoming publication. Nevertheless it can be pointed out here the large impact of the deactivation on the computation of kinetic parameters, the deepest effect being on adsorption entropies and enthalpies, especially widening prediction bands.

Thus, it is utmost important to take into account deactivation profiles while processing data for reaction kinetic modelling. By reprocessing the data according using appropriate deactiva-

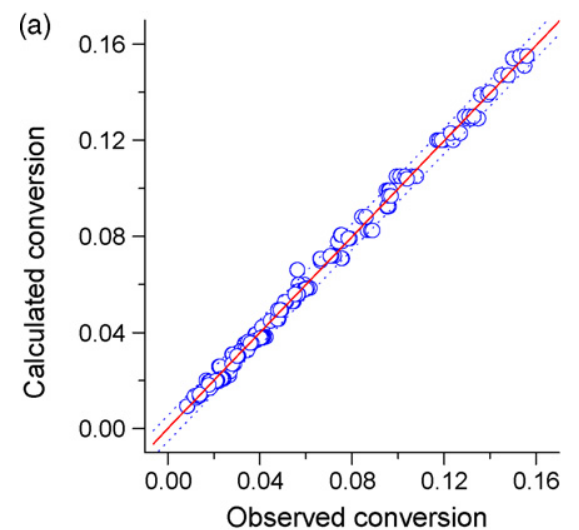

tion models "intrinsic" kinetic parameters $\left(\Delta H, \Delta S, E_{\mathrm{a}}\right)$ can be calculated as catalyst descriptors.

\subsection{Oxygen storage capacity measurements on ceria-doped catalysts}

The results on the OSC measurements by transient parallel experimentations on various ceria-doped catalysts are shown in Fig. 5.

The reference catalyst containing $4.75 \mathrm{wt} \% \mathrm{Pt}$ on high surface area ceria shows a very high OSC whatever the temperature. In contrast, the $2 \mathrm{wt} . \% \mathrm{Pt}$ doped samples prepared for this study show lower OSC under the prevailing conditions, demonstrating the large impact of Pt concentration on OSC extent. As a matter of fact, it was shown elsewhere [46] that part of the Pt loading can form oxide-like clusters inside a fluorite structure, ensuring both an accelerated oxygen diffusion from bulk to surface and along the ceria surface and the storage of overstoichiometric oxygen species (including hydroxyl groups).

Among the 13 dopants, four ( $\mathrm{Pb}, \mathrm{W}, \mathrm{Mo}$ and $\mathrm{Sn})$ allow to increase the OSC by factors of two to three, mostly independently of the temperature within the investigated range. In contrast, vanadium doped ceria shows a continuous increase of the OSC with the temperature to attain values of $120 \mu \mathrm{mol} / \mathrm{g}$.

In general, these results clearly demonstrate that solid state of ceria supports determines the level of OSC and of oxygen transfer dynamics. As a matter of fact, by doping the fluorite structure with exo-cations, various structural effects are induced, such as creating and/or stabilising oxygen vacancies [39], which affects

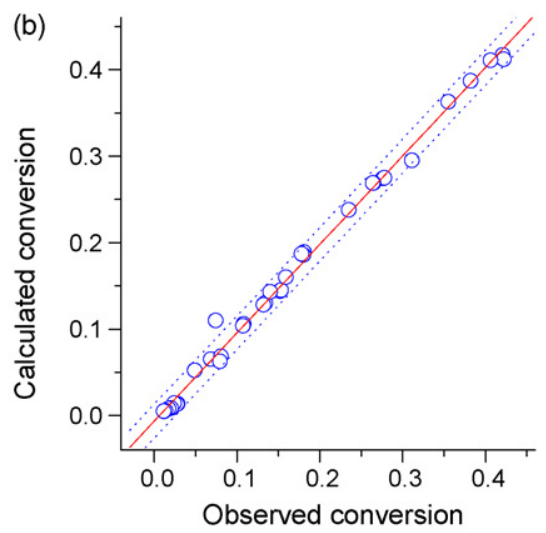

Fig. 4. Parity plots resulting from the kinetic modelling for benchmark catalyst \#7 (a) and catalyst \#3 (b), using non-corrected data. The dashed lines represent the $95 \%$ prediction bands. 


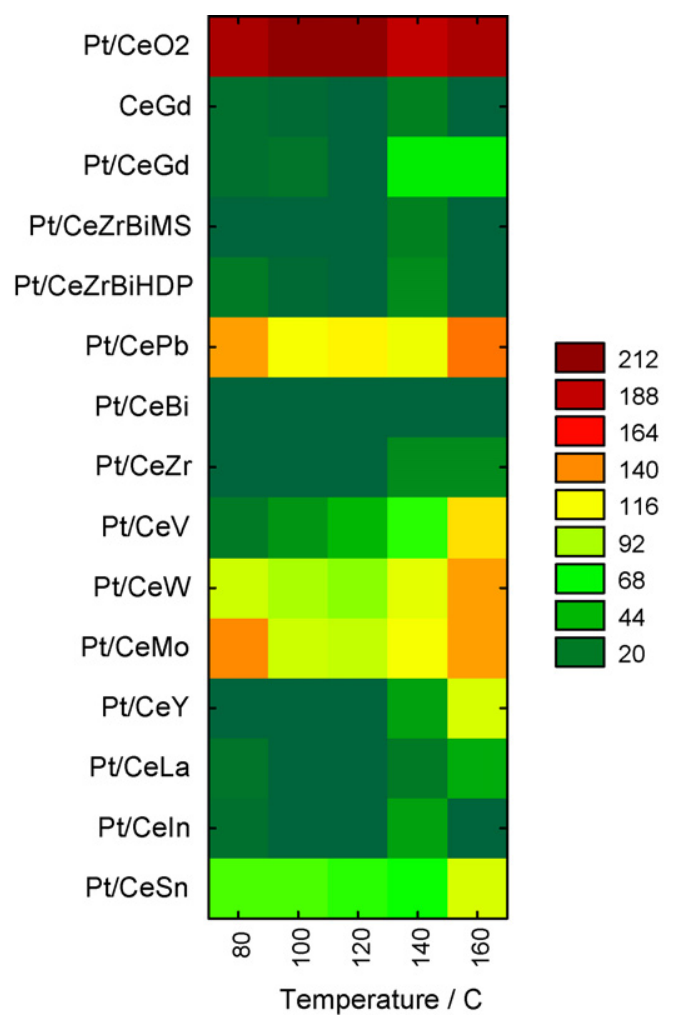

Fig. 5. Oxygen storage capacity (OSC) measurements as a function of the temperature expressed in micromol per gram of catalysts for various $\mathrm{Pt} /$ ceria-doped materials.

directly the intrinsic oxygen diffusion and storage capacity. In the presence of a metal, the reducible ceria provides adsorbed oxygen species that can spill over from the support to the metal particles, the reduced $\mathrm{Ce}^{3+}$ centres being subsequently reoxidized by gaseous oxygen (Eqs. (4) and (5)).

$2 \mathrm{Ce}^{4+}+\mathrm{O}^{2-}+* \rightarrow 2 \mathrm{Ce}^{3+}+\mathrm{O} *$

$2 \mathrm{Ce}^{3+}+1 / 2 \mathrm{O}_{2} \rightarrow 2 \mathrm{Ce}^{4+}+\mathrm{O}^{2-}$

In the presence of hydrogen, ceria can be reduced in the bulk (Eq. (6)), creating anionic vacancies and increasing the mobility of the remaining lattice oxygen atoms. The resulting hydroxyl anions can combine to give water and $\mathrm{O}^{2-}$ (Eq. (7)) with the $\mathrm{Ce}^{3+}$ cations reoxidised by molecular oxygen to $\mathrm{Ce}^{4+}$ as shown above.

$2 \mathrm{Ce}^{4+}+2 \mathrm{O}^{2-}+\mathrm{H}_{2} \rightarrow 2 \mathrm{Ce}^{3+}+2 \mathrm{OH}^{-}$

$2 \mathrm{OH}^{-} \rightarrow \mathrm{H}_{2} \mathrm{O}+\mathrm{O}^{2-}$

A common feature for the above mentioned doping cations favoring the OSC is that the most stable forms of the corresponding oxides are essentially amphoteric or acid except $\mathrm{V}$ which can be either acid or basic. By maintaining an optimized level of surface acidity, these dopants would somehow neutralize ceria basicity (hydroxyl groups) and therefore inhibit formation of stable adspecies such as formates and carbonates which would in turn inhibit oxygen mobility and spillover towards platinum particles [41]. Indeed more advanced catalyst characterization such as in situ FTIR acid-base measurements are required for supporting these assumptions, which also points out the limits of the present HT investigation.

Finally, as reported in Ref. [41], it was also observed for this catalyst library that strong relationships exist between OSC and $\mathrm{CO}$ preferential oxidation in a hydrogen flux (PrOx). As a general trend, it was found that the most performing $\mathrm{CO}$ oxidation samples exhibited the poorest OSC, indicating that excess of oxygen delivered by the system is quite detrimental for the selective oxidation of $\mathrm{CO}$ in the presence of hydrogen.

From an engineering point of view, the method of HT transient OSC measurements at iso-temperature described in the present study was proved to be efficient for assessing key features of oxygen storage and transfer dynamics in diverse materials libraries. This approach can therefore be used as an alternative guideline for optimizing primary screened formulations.

\subsection{Adsorption isotherms of microporous materials}

Adsorption isotherms of gas and vapours in porous materials are obtained by means of breakthrough curve measurements. The experimental procedure is very similar to the OSC measurements described above. Examples of breakthrough curves on seven different microporous materials are shown in Fig. 6. When the selected channel is fed by the gas mixture, some of the gases are preferentially adsorbed as indicated by a decrease of the partial pressure on the mass spectrometer. When the porous network is saturated, the steady-state is achieved and another breakthrough curve can be operated on the next sample. Thanks to the fluidic supply design, when one adsorbant is under testing, the other ones are desorbed under flowing sweep gas (He). As a consequence, desorption is allowed to proceed 15 times longer than adsorption. This operating mode fits well with the usual fact that desorption under sweep gas takes longer time than adsorption, especially when strongly activated adsorption takes place, which can be an issue for fast material screening.

Because of some dead volumes in the tubing and channels, a sharp decrease of the pressure is observed in the first seconds

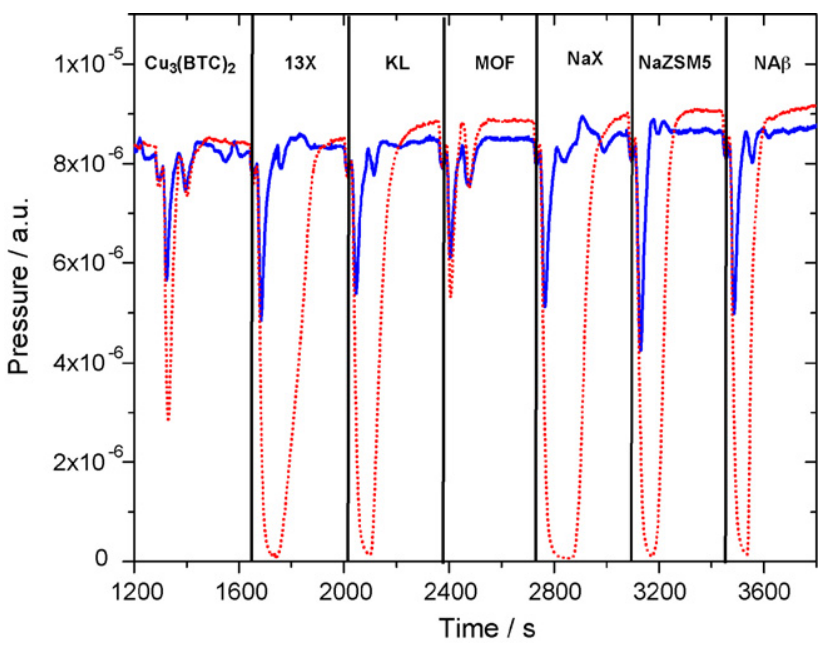

Fig. 6. $\mathrm{N}_{2}-\mathrm{CO}_{2}$ mixture breakthrough curves of seven microporous materials obtained at $100^{\circ} \mathrm{C}$ and five bars total pressure: dashed lines $\mathrm{CO}_{2}$, plain lines $\mathrm{N}_{2}$. 


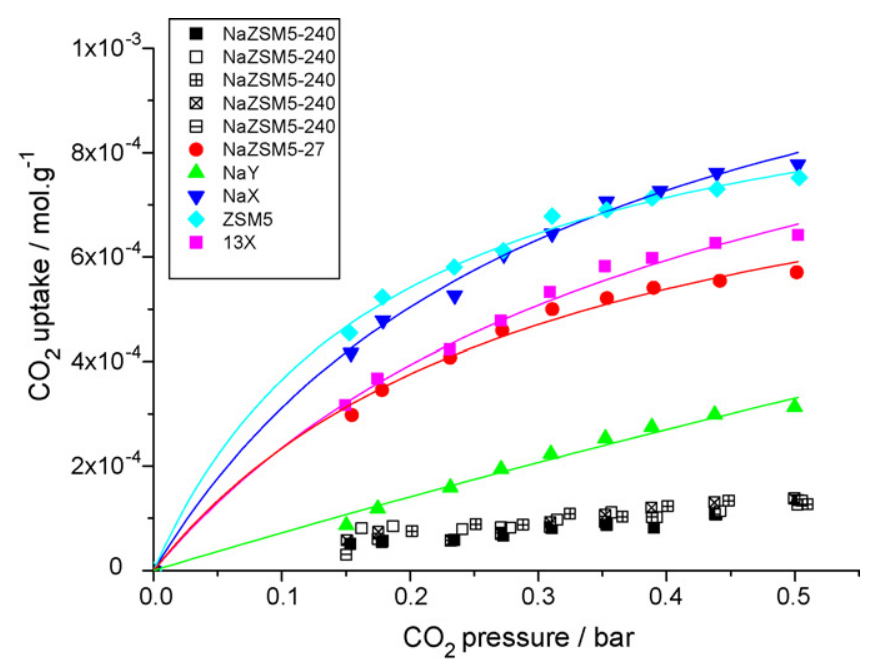

Fig. 7. $\mathrm{CO}_{2}$ adsorption isotherms at $120^{\circ} \mathrm{C}$ from a mixture $\mathrm{N}_{2} / \mathrm{CO}_{2} / \mathrm{He}$ on zeolites. Five replicates of the sample NaZSM5-240 demonstrate the measurement reproducibility.

for all cases. Adsorption capacities are calculated by subtracting blank experiments performed with a non-porous $\mathrm{SiC}$ sample.

From breakthrough curves at different pressure, gas adsorption isotherms were established as shown in Fig. 7.

In good agreement with literature data, $\mathrm{CO}_{2}$ is adsorbed preferentially over $\mathrm{N}_{2}$ on zeolites with a high aluminum content such as $13 \mathrm{X}$ and $\mathrm{NaX}$. In contrast, $\mathrm{CO}_{2}$ adsorption is much less pronounced for NaZSM-5 with a low aluminium content and $\mathrm{Cu}_{3}(\mathrm{BTC})_{2}$ metal organic frameworks due to non polar frameworks [47].

Higher $\mathrm{CO}_{2}$ adsorption capacities are observed for HZSM5, Na-ZSM5-27 and for our reference materials NaX and 13X. The reproducibility was validated using five replicates of NaZSM5240.

Isotherms obtained at different temperatures were modeled using Langmuir equation in order to calculate adsorption parameters. As an example, an activation energy of $20 \mathrm{~kJ} / \mathrm{mol}$ was obtained for the reference $13 \mathrm{X}$ zeolite in good agreement with literature data.

This experimental protocol enables to measure 16 isotherms per day for pure gases or for gas mixtures. From the isotherms, working capacity and selectivity can be calculated as well according Eqs. (1) and (2) at different adsorption and desorption pressure conditions. In turn, the device authorizes a rational screening of adsorbents because it enables to evaluate different materials while defining the best process conditions for each one.

\section{Conclusions and perspectives}

New HT technologies offer the opportunity to increase by several orders of magnitude the number of tested samples. However, instead of screening catalysts against a single criterium such as activity or selectivity, the double approach of HT kinetic and HT characterization was privileged to obtain relevant quantitative information for further Quantitative Structure-Activity Relationship studies, thus providing new guidelines for discov- ery. The case studies presented here showed how to access key parameters/descriptors using HT transient methods for catalysis (hydrogenation reaction), oxygen storage capacity (redox materials) and adsorption capacity (microporous adsorbents). This double approach should facilitate the simultaneous optimization of both material and process engineering.

\section{Acknowledgements}

This work was supported by the EU FP6 Integrated Project TOPCOMBI (Project No. NMP2-CT2005-515792) and IFPLyon.

\section{References}

[1] A. Karlsson, et al., in: Yong Wang, Jamelyn D. Holladay (Eds.), Microreactor Technology and Process Intensification, 914, Oxford University Press, 2005, pp. 66-81.

[2] F. Schuth, et al., Top. Catal. 21 (2002) 55-66.

[3] P. Claus, D. Honicke, T. Zech, Catal. Today 67 (2001) 319-339.

[4] I. Hahndorf, et al., Chem. Eng. J. 89 (2002) 119-125.

[5] M. Lucas, P. Claus, Appl. Catal. A. 254 (2003) 35-43.

[6] U. Rodemerck, et al., Top. Catal. 13 (2000) 249-252.

[7] A. Muller, et al., Catal. Today 81 (2003) 377-391.

[8] P.J. Cong, et al., Angew. Chem. Int. Ed. 38 (1999) 508.

[9] Y.M. Liu, et al., Appl. Catal. A. 254 (2003) 59-66.

[10] M. Orschel, et al., Angew. Chem. Int. Ed. 38 (1999) 2791-2794.

[11] J. Urschey, et al., Solid State Sci. 5 (2003) 909-916.

[12] T. Zech, G. Bohner, J. Klein, Catal. Today 110 (2005) 58-67.

[13] C. Hoffmann, H.W. Schmidt, F. Schuth, J. Catal. 198 (2001) 348-354.

[14] W. Huybrechts, et al., Appl. Catal. A. 243 (2003) 1-13.

[15] C. Kiener, et al., J. Catal. 216 (2003) 110-119.

[16] P.L. Mills, J.F. Nicole, Chem. Eng. Sci. 59 (2004) 5345-5354.

[17] K.S. Oh, Y.K. Park, S.I. Woo, Rev. Sci. Instrum. 76 (2005), No. 062219.

[18] J.M. Serra, E. Guillon, A. Corma, J. Catal. 227 (2004) 459-469.

[19] N. Stoll, et al., J. Autom. Method. Manage. Chem. (2006).

[20] M.L. Bricker, et al., Scaling up of catlysts discovered from small-scale experiments, in: R.A. Potyrailo, E.J. Amis (Eds.), High-Throughput Analysis - A Tool for Combinatorial Science, Kluver Academic/Plenum Publishers, 2003, pp. 581-609.

[21] S. Bergh, High-throughput workflow development: strategies and examples in heterogeneous catalysis, in: A. Hagemeyer, P. Strasser, A. Volpe (Eds.), High-Throughput Screening in Chemical Catalysis, Wiely-VCH, Weinheim, 2004, pp. 63-86.

[22] S. Schunk, et al., Mastering the challenges of catalysts screennig in highthroughput experimentations for heterogeneously catalyzed gas-phase reactions, in: A. Hagemeyer, P. Strasser, A. Volpe (Eds.), High-Throughput Screening in Chemical Catalysis, Wiely-VCH, Weinheim, 2004, pp. 19-26.

[23] J.M. Serra, A. Corma, Two exemplified combinatorial approaches for liquid-solid and gas-solid processes in oil refining and fine chemicals, in: A. Hagemeyer, P. Strasser, A. Volpe (Eds.), High-Throughput Screening in Chemical Catalysis, Wiely-VCH, Weinheim, 2004, pp. 129-150.

[24] J.S. Paul, et al., J. Comb. Chem. 7 (2005) 407-413.

[25] J.A. Moulijn, et al., Catal. Today 81 (2003) 457-471.

[26] W.H. Weinberg, H.W. Turner, Impact of high-throughput screening technologies on chemical catalysis, in: A. Hagemeyer, P. Strasser, A. Volpe (Eds.), High-Throughput Screening in Chemical Catalysis, Wiely-VCH, Weinheim, 2004, pp. 1-15.

[27] J. Perez-Ramirez, et al., Catal. Today 60 (2000) 93-109.

[28] R.J. Hendershot, et al., Appl. Catal. A. 254 (2003) 107-120.

[29] AMTEC GmbH. www.amtec-chemnitz.de.

[30] TOPCOMBI IP. Contract No 515792-2.

[31] A. Stanislaus, B.H. Cooper, Catal. Rev. Sci. Eng. 38 (1996) 159

[32] A.K. Neyestanaki, et al., J. Catal. 218 (2003) 267-279.

[33] V.M. Rahaman, A. Vannice, J. Catal. 127 (1991) 267-275. 
[34] E. Guillon, et al., Catal. Today 65 (2001) 201-208.

[35] A.K. Neyestanaki, et al., J. Mol. Catal. A: Chem. 193 (2003) 237-250.

[36] S. Smeds, D. Murzin, T. Salmi, Appl. Catal. A. 150 (1997) 115-129.

[37] A.E.C. Palmqvist, et al., Nanostruct. Mater. 11 (1999) 995-1007.

[38] M. Mogensen, N.M. Sammes, G.A. Tompsett, Solid State Ionics 129 (2000) 63-94.

[39] G. Rothenberg, E.A. de Graaf, A. Bliek, Angew. Chem. Int. Ed. 42 (2003) 3366-3368.

[40] E.A. de Graaf, et al., Org. Process Res. Dev. 9 (2005) 397-403.
[41] D. Tibiletti, et al., J. Catal. 225 (2004) 489-497.

[42] D.M. Ruthven, S. Farooq, K.S. Knaebel, Pressure Swing Adsorption, VCH, New York, 1994, pp. 208-244.

[43] M. Ackley, S. Rege, H. Saxena, Micropor. Mesopor. Mater. 61 (2003) $25-42$.

[44] J. Delgado, et al., Adsorption 12 (2006) 5-18.

[45] O. Levenspiel, Chemical Reaction Engineering, 2nd ed., 1972, 640 pp.

[46] V.A. Sadykov, et al., Solid State Phenom. 128 (2007) 239-248.

[47] Q.M. Wang, et al., Micropor. Mesopor. Mater. 55 (2002) 217-230. 